\title{
Constelaciones tarológicas. Pedagogías de la performance y lecturas encarnadas a través del Tarot de Marsella
} Tarological constelations. Pedagogy of performance and embodied readings through Tarot

\author{
Marianne COSTA. marianne8costa@gmail.com \\ Javier MORENO. Universitat Miguel Hernández (España).javier.morenop@umh.es
}

Resumen: Las constelaciones tarológicas son un sistema de interpretación tridimensional del Tarot de Marsella con un enfoque artístico y pedagógico. Se enmarcan dentro de la llamada tarología, una corriente interpretativa (no predictiva) desarrollada por Alejandro Jodorowsky y Marianne Costa. Tras observar que la lectura iconográfica suele proceder de una visión ocultista decimonónica, patriarcal y en exceso racional, se ha buscado devolverle una condición encarnada, que tenga en cuenta al cerebro derecho. Tras diez años de puesta en práctica en diversos talleres internacionales, este estudio se ha centrado en continuar poniendo en diálogo la performance con el Tarot de Marsella y en describir su metodología.

En un cruce de saberes donde intervienen disciplinas como la performance, la iconología, la simbología comparada, la pedagogía o el teatro físico se ha realizado una investigación experimental y cualitativa recogiendo numerosos testimonios de personas participantes. Se ha observado que las constelaciones tarológicas pueden devenir en una útil herramienta de creación o pedagogía artística, potenciando la asociación libre de ideas, el pensamiento creativo y la aparición de respuestas inesperadas. La variedad simbólica y de personajes que aparecen en sus escenas, lo convierten en una herramienta inclusiva que permite sinergias de identificación a cualquier persona. Finalmente devuelve la lectura a una condición muldimensional.

Palabras clave: Tarot, pedagogía de la performance, simbología, improvisación, inclusión

\begin{abstract}
Tarological constelations are a Tarot of Marseille tridimentional interpretative system based on an artistic and pedagogical scope. It is framed within tarology, an interpretative (non-predictive) methodology developed by Alejandro Jodorowsky and Marianne Costa. After observing that traditional iconographical reading usually comes from a 19th century, occultist, patrical and excessively rational point of view, we aim to return an embodied condition that takes into account the right side of the brain to it. After ten years of experience in several international workshops, this dissertation is focused
\end{abstract}


on continuing to build a dialogue between performance and Tarot of Marseille and on describing its methodology.

In a cross-meeting of disciplines such as performance, iconography, compared simbology, pedagogy or physical theatre we have carried on an experimental and qualitative investigation that gathers together the testimonies of several participants. We have observed that tarological constelations can end up being a useful creative tool as well as an art pedagogy. It enhaces free association of ideas, creative thinking and the sudden apparition of unexpected responses. The variety of symbols and characters that appear in its scenes make it an inclusive tool that allows synergies of identification able to connect with anybody. Finally, it gives back to tarot reading a multidimensional condition.

Keywords: Tarot, pedagogy of performance, simbology, improvisation, inclusion

\section{Introducción}

El presente artículo aborda la teoría y la práctica de las llamadas constelaciones tarológicas ${ }^{l}$, técnica artístico-pedagógica creada por Marianne Costa. Esta consiste en una interpretacion tridimensional de las cartas de Tarot en la que se establece un espacio-tiempo simbólico y plástico donde las personas que intervienen (performers-reparto, espectadores o ambas cosas a la vez) utilizan dinámicas propias de la performance para propiciar experiencias artísticas multidisciplinares, o para indagar en procesos pedagógicos creativos. Dicha práctica se ha desarrollado en el marco de una extensa investigación de más de veinte años en torno al estudio simbólico del Tarot de Marsella y a la actualización de los sistemas de lectura. Al respecto y como antecedentes al estudio que nos ocupa resulta imprescindible mencionar $L a$ vía del Tarot (Costa, Jodorowsky, 2004). Una obra literaria de corte pedagógica que parte de la experiencia artística y terapéutica desarrollada por el cineasta Alejandro Jodorowsky durante décadas con el Tarot de Marsella, y que formaliza, junto a la escritora y artista Marianne Costa, todo un sistema nuevo de aprendizaje y lectura con el famoso juego de naipes. Convirtiéndose en best-seller, el libro de Jodorowsky y Costa fue traducido a varios idiomas del francés (inglés, italiano, castellano, japonés, alemán o portugués) y se utilizó como material pedagógico para numerosos talleres impartidos en diferentes países. El sistema, denominado en el libro como tarología y nombrado después de manera popular por los grupos de practicantes como tarot evolutivo, retomaba los presupuestos simbólicos y numerológicos desarrollados a principios del siglo XX por Paul Marteau (1985), y se enriquecía de experiencias propias. El tarot evolutivo no era ninguna baraja nueva de Tarot, sino una renovada deontología que escapaba a la tradicional lectura adivinatoria. El tarot evolutivo, primeramente llamado tarología, procuraba ayudar a cualquier consultante a clarificar y entender cuestiones presentes a partir de su pasado y de las probabilidades futuras; no conjuraba profecías:

1 El término proviene de las llamadas constelaciones familiares, concepto psicoterapéutico en torno a los roles familiares que fue empleado por Alfred Adler y Carl Jung, pero que Bert Hellinger sistematizó como técnica. 
Me percaté de que las antiguas formas de lectura del Tarot recopiladas en los tratados "tradicionales" no me servían de ayuda. Se habían establecido para predecir el futuro, cosa que, como ya he señalado, me parecía infantil y deshonesta. Predecir que los acontecimientos pueden suceder los hace suceder: el cerebro tiende a la realización automática de las predicciones. Necesitaba un sistema que me permitiera leer el presente [...] comencé a utilizar el Tarot como un test psicológico, inspirándome en el de Rorschach y más tarde en otras formas que hacen presentes los contenidos inconscientes (Costa, Jodorowsky, 2004, p. $491-492)$

Una herramienta que se puso a disposición de la técnica terapéutica jodorowskyana-costiana de estudio del árbol familiar, desarrollada ampliamente en el libro Metagenealogía (Costa, Jodorowsky, 2011). Como compendio visual simbólico, el Tarot de Marsella se proponía también como una herramienta adecuada para la creación artística.

Tras catorce años de la publicación del libro y de la aplicación de la metodología tarológica con miles de personas en numerosos cursos, talleres, consultas y conferencias presenciales u online, Costa actualizó muchos de los presupuestos de La vía del Tarot y en 2018 publicó la obra Tarot pas à pas $^{2}$, libro que ya ha sido editado en Italia, Latinoamérica y España. Es aquí donde se exponen por primera vez ejercicios que trascienden la ortodoxia de la lectura de tarot como conversación simbólica entre 2 o más personas, y se incluyen, entre otros, ejercicios para re-dibujar y dotar de nuevos cromatismos al tarot, esculpir arcanos o crear relatos literarios con ellos:

El Tarot no se limita a la lectura. Sus imágenes en dos dimensiones tienen el poder de animar un mundo vivo, en relieve, que se mueve en el tiempo y en el espacio... Reducirlo a una serie de imágenes que interpretamos es privarse de una relación rica y creativa con él. Reducir el Tarot a la segunda dimensión, a imágenes con leyendas y a unas pocas explicaciones verbales es privarse de su capacidad de resonancia: achatarlo. (Costa, 2021, p. 359)

Es aquí donde se expuso por primera vez de manera resumida la técnica que ocupa nuestro estudio y cuyo objetivo principal es 1) poner en diálogo la performance y el Tarot de Marsella para la generación de herramientas inclusivas y encarnadas de pedagogía creativa y praxis artística, y 2) explicar la metodología para su práctica, un modo de empleo.

Ponemos el foco de interés en la constelación tarológica como lectura-interpretación en movimiento que pone en relación el cuerpo de la persona consultante y los símbolos contenidos en el Tarot de Marsella. La herramienta se ha puesto en práctica y se ha expuesto a diferentes variables en los numerosos talleres y cursos monográficos (alrededor de una treintena) que la autora ha impartido sobre las constelaciones tarológicas en diferentes localizaciones como en México D.F. (15-16/11/2014), Punta del Este, Uruguay (2324/05/2015) o Barcelona (18/10/2018). La constelación tarológica se ha puesto en práctica durante más de 10 años, desde 2010 hasta la actualidad, en diversos talleres y cursos internacionales en Latinoamérica (Argentina, México, Uruguay, Perú, Chile, Venezuela y Bolivia) y Europa (Francia, Italia y España). La información ha sido recogida a través de una labor documental fotográfica y también de numerosos testimonios (orales y escritos) las personas participantes. Estos eventos estaban dirigidos a un público diverso y ecléctico

2 Edición original en francés: Costa, M. (2018). Le Tarot pas à pas. París, Francia: Éditions Dervy 
interesado en la simbología del tarot y en su uso no convencional, pero que además tiene inquietudes artísticas (desde el grado del amateur al del profesional del ámbito artístico, escénico, musical o literario). Habiendo acudido tanto hombres como mujeres, observamos siempre una mayoría de mujeres y un rango amplio de edad que oscila entre los 20 y 65 años aproximadamente, con mayor frecuencia de personas de mediana edad.

\section{Marco teórico}

\section{Acercamiento histórico al Tarot de Marsella}

De origen incierto y autoría desconocida, el Tarot de Marsella se conformó en Europa a mediados del siglo XV en el contexto histórico-cultural de la mística renacentista ${ }^{3}$, la alquimia $4^{4}$, los "Triunfos" petrarquistas ${ }^{5}$ y la literatura del amor cortés (Costa, 2018). Se conformaba así un sustrato simbólico, un imaginario hermético repleto de numerosas alegorías que se compartían tanto en la cultura popular (ya fueran fiestas o el propio Tarot) como en otras prácticas artísticas legitimadas (pintura, escultura o teatro) (Dummett, McLeod, 2004). Por citar algunos de estos símbolos, observamos la aparición de tres de las cuatro virtudes cardinales (Justicia, Fuerza y Templanza), el Arcano XIII mostrando una representación recurrente de La Muerte con su guadaña o las referencias a la literatura caballeresca a través de las figuras de la Reina y el Caballero. Con una marcada iconografía medieval y tras la aparición de algunos modelos italianos como los llamados ViscontiSforza (c.1450) o los de impronta humanista como el Tarot de Mantegna (c. 1470) o el Sola Busca (c. 1448 - 1511).

El juego se acabaría estandarizando a partir del Renacimiento como un juego de 78 cartas, de las cuales encontramos 22 triunfos denominados Arcanos Mayores y 56 llamados Arcanos Menores, compuesto este último grupo por los valores del I al X en cuatro palos tradicionales (a saber: Espadas, Copas, Oros y Bastos) y sus correspondientes Figuras (Paje, Rey, Reina, Caballero). Su uso como juego de mesa se popularizó hasta el siglo XIX y se mantiene actualmente en algunos países como Francia. Fueron las voces de ocultistas decimonónicos, como los parisinos Eliphas Lévi o Papus ${ }^{6}$, quienes elaboraron todo un discurso mágico en torno al uso del mazo como herramienta mágica, predictiva y espiritual. Y de ahí florecieron otros mazos de Tarot y oráculos con nombre y apellidos de los cuales algunos mantuvieron la estructura, el contenido y el simbolismo de los Arcanos originales, y otros no. Antoine Court de Gebelin, ya en 1781, creía en la mística inherente del oráculo y que fue la propia ignorancia sobre su significación profunda la que le dejó traspasar siglos de persecución inquisitorial bajo el disfraz de mero juego. Ya en el siglo XX, Paul Marteau encaminó una vía de investigación tarológica que heredaron y continuaron Alejandro

3 Como por ejemplo las obras literarias renacentistas de Santa Teresa de Jesús (1515 - 1582), San Juan de la Cruz (1542 - 1591) o Fray Luis de León (c. 1527 - 1591); o antecedentes medievales tales como el de la mística germana Hildegarda de Bingen (1908 - 1179) o la británica Juliana de Norwich (1342 - 1416).

4 Con representantes como Nicolas Flamel (París, c. 1330 - c. 1418) o Paracelso (Zurich, 1493 - 1541).

5 La obra se concluyó en 1374 y será a partir del siglo XVI con el advenimiento de la imprenta que obtuvo una gran difusión a lo largo de Europa.

6 Con sus respectivo textos Dogma y Ritual de Alta Magia (1854) y El Tarot de los bohemios (1889) 
Jodorowsky y quienes suscriben este texto. Un breve acercamiento a la historia del juego nos permite observar que se trata de una obra colectiva depositaria de numerosos saberes iconográficos alrededor de la cual han surgido y continúan surgiendo diferentes sistemas de interpretación de los mismos.

\section{La interpretación simbólica como espacio plástico}

En las láminas del Tarot de Marsella vemos desfilar personajes reales del contexto social europeo renacentista tales como Papas (y posibles Papisas), emperadores y emperatrices, damas, ermitaños anacoretas y pajes, así como alegorías recurrentes en torno a la justicia, la muerte o los astros, o personajes de ficción como el Diablo. Abordar la interpretación simbólica de los Arcanos Mayores y Menores trasciende los límites del presente estudio. La gran diversidad iconográfica y de personajes que ofrece el juego, como si de una película con un amplio elenco se tratase, permitiría una amplia gama de posibilidades de identificación por parte de quienes lo jugaban. La cantidad y variedad de símbolos que contiene dicho juego podrían dotar a esta obra de arte sincrónica de una potencialidad proyectiva donde cualquier persona, independientemente de su diversidad de género, sexual, cultural, generacional, funcional o de clase social, puede identificarse.

Rescatamos esa dinámica proyectiva de identificación para el uso encarnado del Tarot, una suerte de transferencia positiva (Freud, 1912) donde la persona performer o espectador no se puede demarcar de los poderes de moción inconscientes, reprimidos o no, con las posibles identificaciones. La transferencia freudiana podría ser vista tanto como la primera y gran resistencia en cuanto a la identificación del terapeuta con figuras infantiles del paciente y experiencias traumáticas (transferencia negativa) como con recuerdos afables (transferencia positiva). En el ámbito de una pedagogía de la performance con el Tarot si bien pueden emerger aspectos terapéuticos, estos no son puestos bajo la óptica de análisis de un terapeuta, sino que, en todo caso, son mediados hacia experiencias artísticas donde la capacidad de transferencia se entiende en sentido amplio (el mismo que podría determinar la preferencia por un color, forma o ritmo).

Un rasgo común que observamos entre la constelación tarológica y la interpretación ortodoxa del Tarot de Marsella es la propia especificidad subjetiva de la lectura. Cada lámina es un conjunto iconográfico que remite a correspondencias asumidas y estables por una colectividad (significados denotativos) pero que tienen el espacio de libertad suficiente para ser sometidos a la interpretación subjetiva y la transferencia de quien interactúa con ellas (significados connotativos). Asimismo, dichos símbolos establecen relaciones entre sí, interactúan, como las miradas de los personajes, establecen relaciones intratarológicas; a su vez esas imágenes dispuestas en el espacio establecerán relaciones extratarológicas con las personas que interactúan con ellas. Dicha versatilidad de relaciones e interpretaciones simbólicas favorecen un espacio plástico de transferencia para la experimentación creativa en vivo. Los Arcanos del Tarot de Marsella devienen en resortes o detonadores para desencadenar acciones e interacciones que se producen de manera improvisada. Tal y como se verá más adelante en la descripción del modo de empleo, las constelaciones tarológicas parten de una serie de variables de tiempo, espacio y elementos con los que interactuar, 


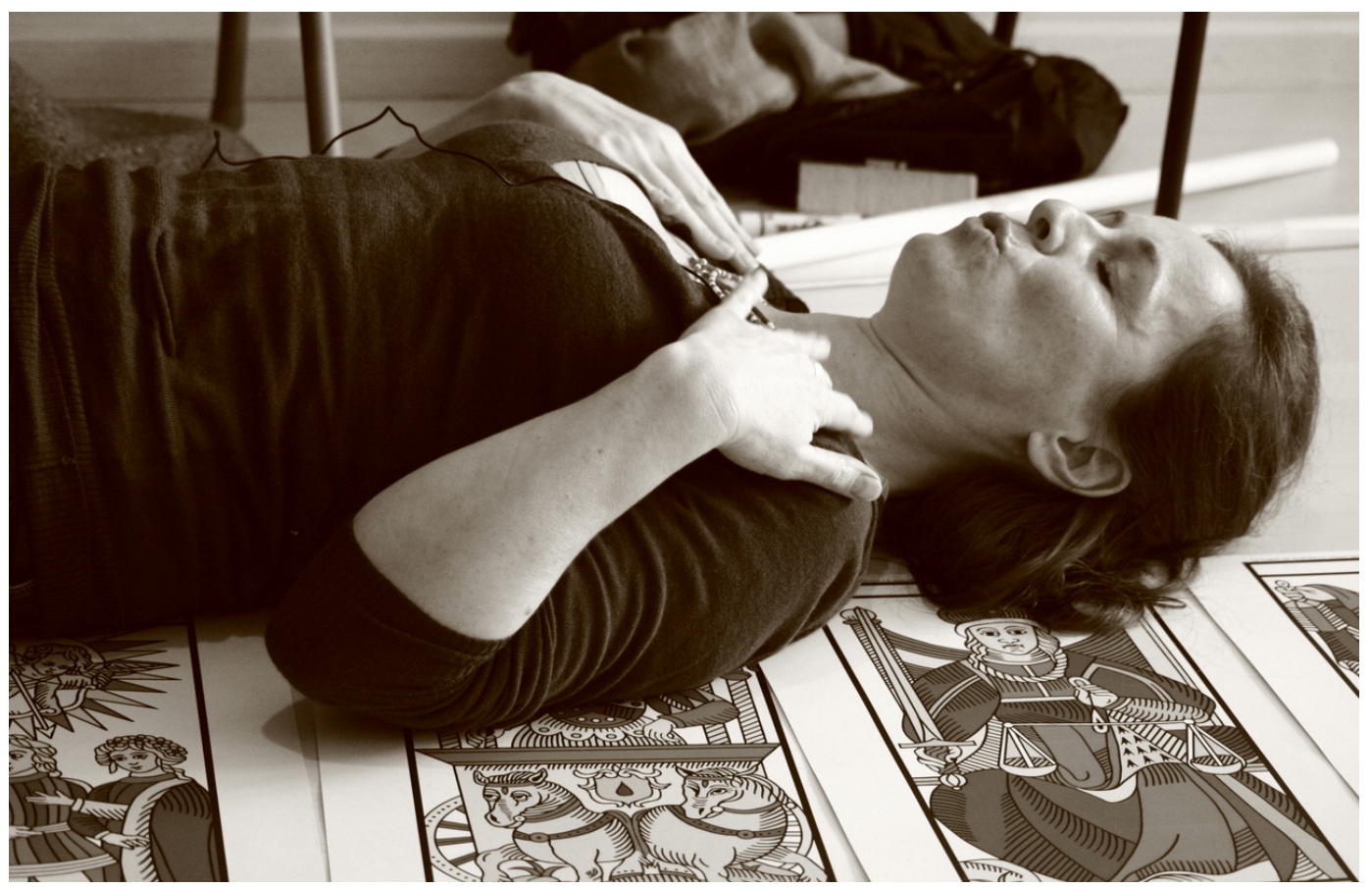

Figura 1. Marianne Costa interactuando a través del cuerpo y el soplo con diferentes Arcanos del Tarot de Marsella durante una constelación tarológica.

pero no se establecen partituras previas. Las constelaciones ayudan a pensar y a crear, son más bien una pedagogía y (auto)pedagogía de procesos artísticos que pueden devenir o no en creaciones posteriores.

La performance clásica, en el sentido de acción artística, ofrece estructuras y metodologías para establecer ese espacio plástico para una lectura improvisada ${ }^{7}$, un espacio de libertad donde cualquier persona puede ser incluida.

La utopía no tiene lugar real, es simplemente un lugar ideal, libre de toda contaminación temporal [...] Si la utopía no se sitúa en ninguna parte, la performance al contrario está en todas partes [...] En la performance, el espacio es abierto, como la obra, lo más abierto posible, en todos los sentidos del término, físico y mental, pues ella, la performance, puede transformarse in situ, como he dicho antes. En la performance todo es posible. (Ferrer, 2007)

Para Esther Ferrer no se da la delimitación de un decorado teatral ni existe la distancia física, sino que la relación entre performers y público es directa. En el caso de las constelaciones tarológicas el espacio es habitado solo por personas participantes, co-creadoras de obras individuales o colectivas; todo es visible. Tampoco existen guiones previos o personajes que interpretar, como en el teatro; si bien el Tarot facilita de por si un rango amplio de posibilidades interpretativas dada la galería de personajes que proporciona. Aquí si daríamos

7 Si bien tampoco descartamos las acepciones de la voz inglesa performance donde se incluiría también cualquier evento o puesta en escena teatral y/o musical, no únicamente como acción artística. 
cabida al personaje y la potencialidad dramática de las personas participantes más allá de una noción de performance pura no representacional. En ese sentido la práctica se alinea en muchos aspectos con las pedagogías del teatro físico desarrollado por Jacques Lecoq en su escuela. Tal es el caso de la consideración del aspecto lúdico en sus pedagogías: "El juego como puente entre lo real y lo imaginario es apreciado en sus múltiples direcciones como: un principio dinámico; la energía que intercambian los actores; un medio de crear nuevas relaciones entre los estilos, entre la palabra y el gesto; planta la relación entre libertad y condicionantes; el carácter lúdico y de plenitud; el valor comunicativo" (Salvatierra, 2007, 251). También resultaba de relevancia la técnica psicoterapéutica del focusing desarrollada por Eugene Gendlin y su noción de la sensación sentida (Gendlin, 2020), así como la condición de experiencia umbral donde la experiencia estética teatral deviene en una suerte de espacio-tiempo liminal, ritual y transformador (Fischer-Lichte, 2003). En una lectura 2D se extraen naipes por azar, sin verlos previamente. En el caso de la constelación tarológica, una lectura $3 D$, los naipes son desplegados previamente y son las elecciones de las personas que intervienen, intentando que se basen en la espontaneidad, las que determinarán un tipo de lectura u otra.

Se tuvieron en cuenta variables características de la pedagogía de la performance tales como el cuerpo, la presencia, el tiempo y el espacio. Partiendo de una presentación a priori no dramatizada, la interacción de múltiples relaciones simbólicas entre las imágenes y la colectividad de participantes, se da sin embargo la posibilidad de que exista la representación $\mathrm{y}$, por tanto, lo teatral. Otras de las nociones a tener en cuenta son el uso del juego, en el sentido de una hermenéutica gadameriana ${ }^{8}$, y el azar. Características clave ambas de cualquier lectura ortodoxa de cartas: se trata de un juego y no sabemos que cartas sacamos.

La motivación primera de Costa para diseñar esta técnica fue motivada por su experiencia en talleres impartidos en numerosos países. Se observó que la lectura 2D podía apuntar hacia la tridimensionalidad, hacia la llamada cuarta dimensión en tanto que espacio-tiempo y también a esa quinta dimensión como espacio ceremonial, liminal o umbral, en palabras de Fischer-Lichte. Se observó que la consideración entorno al Tarot en Europa solía estar vehiculada por una visión ocultista decimonónica, "un libro" donde se entendían las láminas como compendios de símbolos a descifrar, pero donde se perdía un contacto más orgánico y gestáltico con la imagen, lo sensorial y, por tanto, con el cerebro derecho. Algo que el arte articulaba por derecho propio.

\section{Metodología de las Constelaciones tarológicas}

A nivel metodológico se ha partido de unos presupuestos procedimentales propios de la experiencia artística y de la pedagogía del arte de quienes suscriben el texto en el campo del teatro ${ }^{9}$, la performance, la música y las artes visuales. Se ha inducido una investigación experimental y cualitativa que se traduce en un estudio experimental prolongado

8 Al respecto se puede consultar el texto Gadamer, H-G. (1991): La actualidad de lo bello. Barcelona: Ediciones Paidós Ibérica, sobre la consideración co-creadora del público.

9 En especial, y de parte de Marianne Costa como creadora de las constelaciones tarológicas, en el campo del teatro físico y de sus estudios en la Escuela Jacques Lecoq a principios de los noventa. 
en el tiempo durante más de 10 años y que todavía podríamos considerar abierto y en mutación constante. Las experiencias vividas quedaban documentadas en a) un archivo fotográfico abierto donde se ponen en relación los Arcanos utilizados con las prácticas performáticas realizadas, y en b) testimonios orales o escritos. Las diferentes variables de espacio, tiempo, cuerpo-presencia y diversidad de las personas participantes en el estudio han ido paulatinamente arrojando luz sobre los modos más adecuados de formular una sistematización del método.

\section{Encrucijadas de saberes}

Resulta importante matizar metodológicamente la naturaleza mestiza e interdisciplinar de este tipo de práctica ya que se encontraría en un cruce saberes entre la obra artística, el arte terapéutico, la pedagogía del arte y la interpretación simbólica. Dicha cuestión determinará sobremanera el proceder del estudio y de la técnica. Entendemos la encrucijada como un espacio epistemológico para el cruce horizontal de saberes (x) y de posibilidades de empoderamiento y tránsito en el eje vertical (y). Desde ese lugar o cruce de lugares establecemos un marco teórico basado, por un lado, en los estudios visuales, donde intervienen disciplinas como la simbología comparada, la iconología (Panofsky, 2001), la investigación aplicada de la artes visuales, escénicas y literarias, el storytelling, la pedagogía de la performance y el teatro fisico, o la a/r/tografia como "indagación de vida [...] de estar atentos a la vida en el tiempo, estableciendo relaciones entre cosas que no parecen estar relacionadas, y sabiendo que siempre hay conexiones por explorar" (Irwin, 2004, 108).

Usamos conscientemente la noción de encrucijada en tanto que suma al pensamiento racional el paradigma mágico, visto este último generalmente como elemento estigmatizador y deslegitimador de prácticas consideradas supersticiosas, atrasadas, y que movimientos como el simbolismo, el dadaísmo, el expresionismo, el surrealismo, el teatro del absurdo o la performance de carácter ritual se han encargado de poner en valor. Una colonialidad epistemológica donde el pensamiento racional cartesiano pertenecería al orden del norte, del colonizador, y el pensamiento mágico, al orden del sur, del subalterno colonizado:

La Pedagogía de las Encrucijadas opera directamente para la ampliación de las posibilidades explicativas del mundo y, en consecuencia, en la intersección (el cruce) de estas posibilidades [...] La Pedagogía de las Encrucijadas borra la lógica de un mundo dividido [...] Desde la perspectiva de la encrucijada, la transgresión de lo que Fanon llamó colonialismo epistémico emerge como un acto emancipatorio que produce el arrebatamiento de aquellos marcados por la condición de subalternidad (colonizado), así como de aquellos montados por la condición de explotadores (colonizadores). La práctica de la encrucijada como un acto descolonial no apunta a la subversión, al mero intercambio de posiciones, sino a la transgresión. (Rufino, 2020)

Tanto en la pedagogía de la encrucijada de Rufino, como en la noción de lo daimónico de Patrick Harpur ${ }^{10}$, se viene a enaltecer la gnosis, la visión y la epifanía, cuestiones que entroncaban con las tradiciones místicas de todas las culturas y que configuraban una

10 Para más información sobre un estudio sincrónico comparado de visiones y apariciones, se puede consultar Harpur, P. (2007). Realidad daimónica. Girona: Atalanta. 
esfera de saberes al margen de la norma racional. Un acceso performativo y simbólico al hemisferio derecho.

\section{Resultados}

Tabla 1

Tabla de descripción de actividad de Constelación tarológica básica con pregunta.

\section{CONSTELACIÓN TAROLÓGICA BÁSICA CON PREGUNTA}

Descripción de la actividad

\section{A quién va dirigido:}

Abierto a todos los públicos, especialmente a artistas visuales y/o escénicos, personas con inquietudes artísticas, personas con intereses en el análisis simbólico, la iconografía y el Tarot de Marsella.

\section{Numero de personas:}

8 personas mínimo moderador/a, 2 espectadores y 5 performers)

\section{Tiempo estimado:}

1 hora - 1 hora 30 minutos aprox.

\section{DESCRIPCIÓN DE LA ACTIVIDAD}

Realizar ejercicios de respiración, relajación y/o meditación durante unos minutos para "cortar" con la mente analítica y entrar en un espacio-tiempo liminal. La persona para quien se va a constelar plantea la pregunta. Esta puede incluirse o no en la constelación.

Ruta de acceso I (azarosa): Contactar con la pregunta. Transitar el espacio caminado de manera lenta y consciente. Con la mente lo más serena posible, observar los Arcanos y centrar la atención en lo que más llama la atención (sea atracción o repulsión).

Ruta de acceso II (dirigida): Contactar con la pregunta. Elegir un Arcano específico que nos llame la atención y conectar con él de manera intuitiva e implicando al cuerpo.

1. Una vez hemos elegido la carta con la que queremos trabajar, interactuamos con ella. Es idóneo incluir al cuerpo realizando pautas de expresión corporal improvisadas. Podemos tocarla, olerla, mirarla mientras bailamos, dejarnos mecer por un ritmo que marque la imagen, repetir una acción de manera repetitiva o dejar que en nuestra mente se formen visualizaciones inesperadas. Lo más importante es implicar al cuerpo y dejar que sea él quien piense y actúe. Se puede permitir la encarnación de algún personaje del tarot o el desarrollo de una acción, literal o no. 
2. Permitir que surja el contacto con otra persona de manera no verbal, con el movimiento del cuerpo o la afinidad de la actividad que se esté realizando. Después incluir a otra o más personas (se recomienda que haya un mínimo de 5 personas y 5 cartas). La acción conjunta debe alcanzar un clímax de improvisación.

El grupo puede intercambiar opiniones y definir una pieza performática, musical, teatral, artística, literaria o todo a la vez. Interpretar la pieza a modo de respuesta a la pregunta de la persona consultante (esta puede estar integrada en la propia respuesta o no, y haber participado en su diseño o no).

El primer resultado que presentamos al estudio es una definición estable de la actividad Constelación tarológica básica con pregunta (Tabla 1). Esta ha sido desarrollada en varias fases. La $1^{a}$ fase comenzó con un pequeño grupo de estudiantes de Marianne Costa en París, donde se pusieron en práctica las primeras experimentaciones y se fue definiendo la técnica a través del ensayo-error mediante el uso de láminas en blanco y negro ${ }^{11}$. Ahí se fueron clarificando los presupuestos de la actividad y posibles variables (introduciendo cartas improvisadas, dirigiendo el enlace entre personas, incluyendo elementos externos, etc.). La $2^{\mathrm{a}}$ fase continuó con la divulgación y puesta en funcionamiento de la técnica en diversos talleres impartidos por Marianne Costa (a veces acompañada de colaboradores) empezando en abril de 2013 en Italia y continuando por diversos lugares de Latinoamérica (México, Chile, Perú, Uruguay, Argentina, Venezuela y Bolivia), Estados Unidos (San Francisco y California) Canadá (Quebec) y Europa (Francia, Italia y España). Se realizaron alrededor de una treintena de cursos, algunos dedicados en exclusiva a la técnica, y otras donde se ponía en comunicación con otras prácticas. Más que como una técnica cerrada, la constelación tarológica se propuso siempre como un punto de partida, un espacio abierto de experimentación donde los estudiantes utilizaban las imágenes facilitadas por el Tarot de Marsella como conglomerados simbólicos para la elaboración de obras improvisadas, performáticas y multidisciplinares (que podían incluir, por ejemplo, teatralizaciones, pintura en movimiento o música).

Todos ellos ayudaron a definir la actividad de acuerdo a diferentes posibilidades y objetivos: constelaciones tarológicas con pregunta (tal y como describimos aquí), constelaciones tarológicas con pregunta y elección de reparto (donde se hace una tirada previa, interpretada o no, se eligen a las personas que interactúan con las cartas y tras la constelación se añade lo vivido para configurar una lectura) o constelaciones tarológicas sin pregunta (donde suprimiendo la pregunta se efectúa una experimentación con arcanos que elegimos o encontramos por azar).

11 Producidas por el artista peruano Lorenzo Ferreyros en 2012. Este fue el germen de la posterior producción del Proyecto DelTarot \#1 (París-Alicante, 2020); una revisión digital en blanco y negro del Tarot de Marsella Pierre Madenié de 1709, dirigida por los autores de este texto e ilustrada por Eric Carpe. Se observó que los colores del Tarot correspondían a decisiones de los diferentes maître cartiers y la opción sin color ofrecía posibilidades mayores de proyección durante la lectura. 


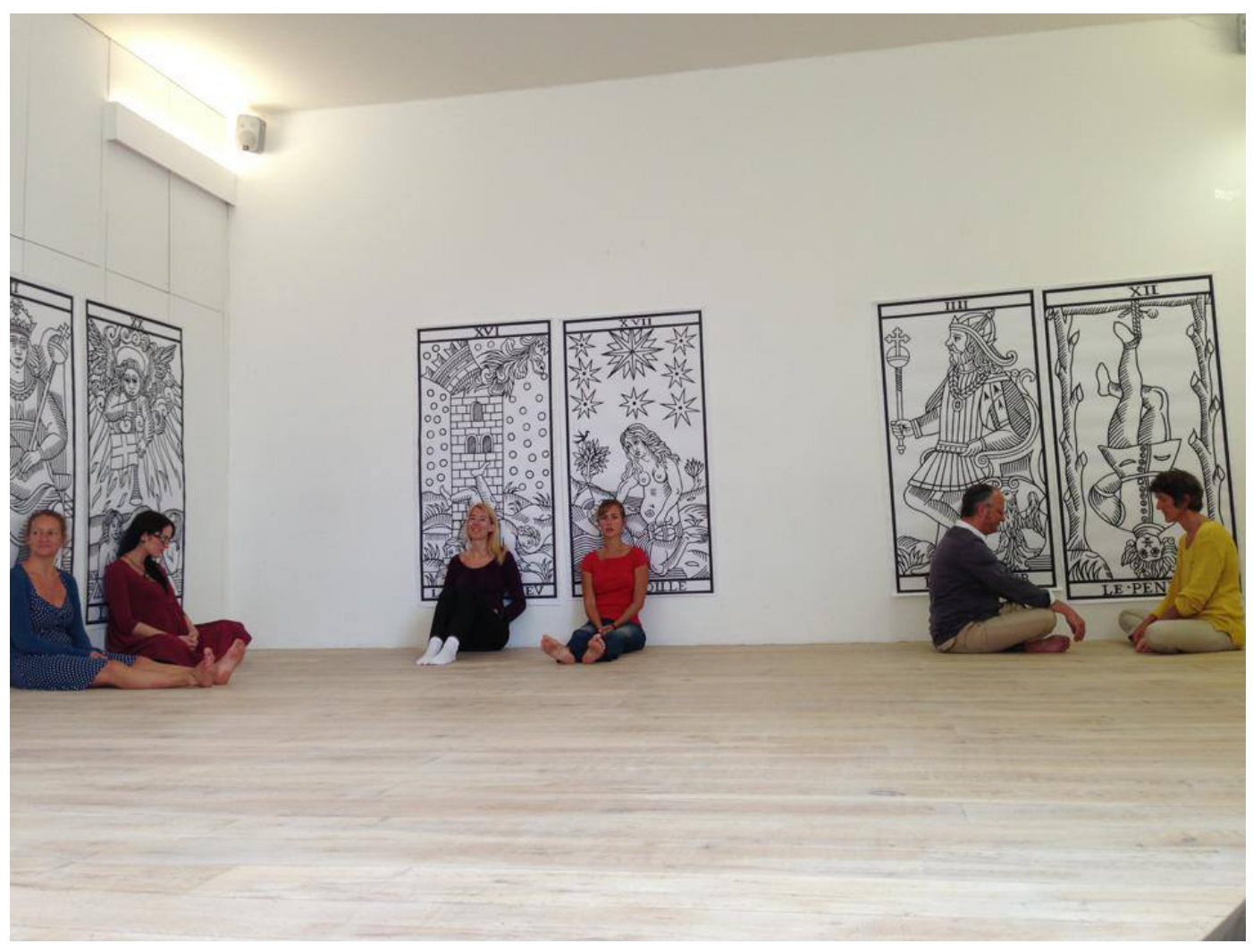

Figura 2. Grupo de experimentación en constelaciones tarológicas durante su $1^{\mathrm{a}}$ fase

Durante la $2^{\mathrm{a}}$ fase se tomaron registros fotográficos, y se recogieron testimonios orales y escritos de personas que participaron en constelaciones o generaron diferentes sinergias a partir de ellas. Aquí se transcriben algunos ejemplos:

En medio del espectáculo los espectadores pueden elegir un arcano a partir de una pregunta y la respuesta es una improvisación teatral inspirada en el arcano, dándole voz y cuerpo o dejándome llevar por la atmósfera o el paisaje que la carta inspira [...] Creé varios espectáculos inspirados en los arcanos del tarot. Por ejemplo, para la creación de uno de ellos, antes de comenzar los ensayos, sacaba dos arcanos mayores a partir de los cuales surgían improvisaciones, personajes o historias que aportaron al desarrollo de la dramaturgia. Durante la creación de otro espectáculo me apoyé en la Emperatriz para el personaje principal y su contracara, el arcano XIII. (mujer de 37 años, lectora de tarot, actriz y cantante)

Escribía narraciones basadas en tiradas de tarot, donde los arcanos marcaban el carácter de los personajes y el orden de los arcanos en la tirada marcaba la relación entre los personajes. Este método me ayuda a narrar algo que yo no había decidido, lo cual me daba una tremenda sensación de libertad. (hombre de 41 años, narrador)

Recuerdo una experiencia con el Arcano X. En grupo realizamos vueltas en espiral durante unos minutos. Luego se plasmó en un dibujo libre y apareció una espiral que me conectó 
con una espiral corporal y energética que salía de mi plexo solar. Hubo ahí una relación entre la escenificación del arcano, el dibujo y mi cuerpo. (mujer de 35 años, psicóloga, terapeuta Gestalt y taróloga)

Una práctica que suelo realizar es mezclar las 78 cartas y sacar entre una y tres cartas. Luego, sin pensarlo mucho y sin analizar el mensaje de forma intelectual, escribo dejando que las palabras cobren vida resonando con las cartas consteladas, a veces mezclando las imágenes de las cartas con cosas del mundo concreto que me han sucedido ese día (o que tenga muy presentes). El resultado suele ser una especie de poema crudo del cual a veces extraigo fragmentos para retrabajarlos y convertirlos en letras de canciones (hombre de 38 años, músico y estudiante de Tarot)

A partir de diferentes experiencias generadas mediante la constelación tarológica se han derivado eventos como por ejemplo el festival Arte Arcano (celebrada en 2017 y 2020 en Barcelona y en Paris en 2019), donde se propone una convivencia interdisciplinar de teatro, danza, dibujo, fotografía, performance y lecturas en vivo alrededor del Tarot de Marsella durante varios días. Del mismo modo Marianne Costa, en colaboración con el guitarrista Claudio César y la pianista Eugenia Guzmán, puso en funcionamiento el espectáculo Tarotango que fue estrenado durante el II Congreso Internacional de Baraja y Tarot (10/03/2020, Madrid).

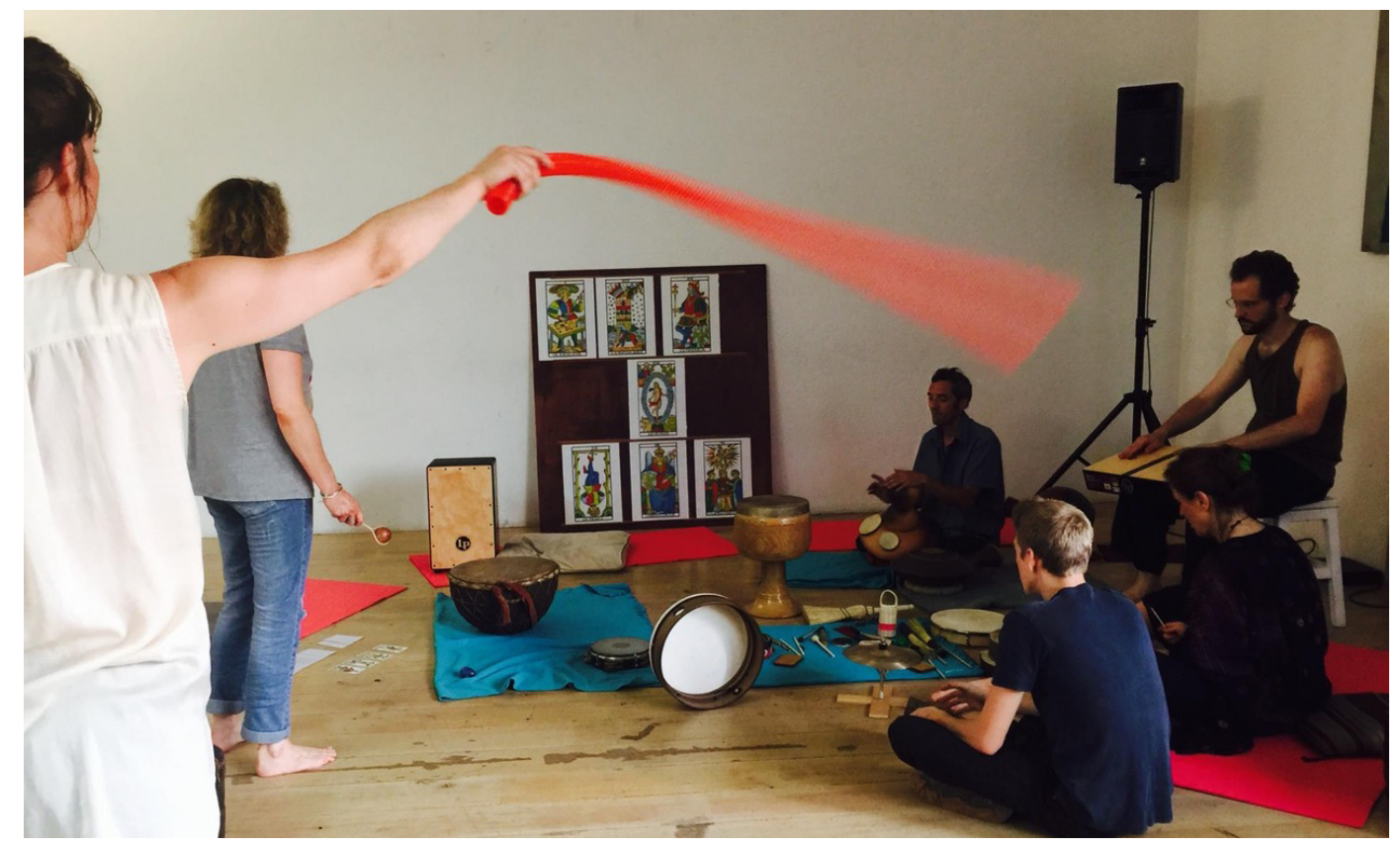

Figura 3. Instantánea de performance musical con el Tarot de Marsella realizada en París (junio 2015). 


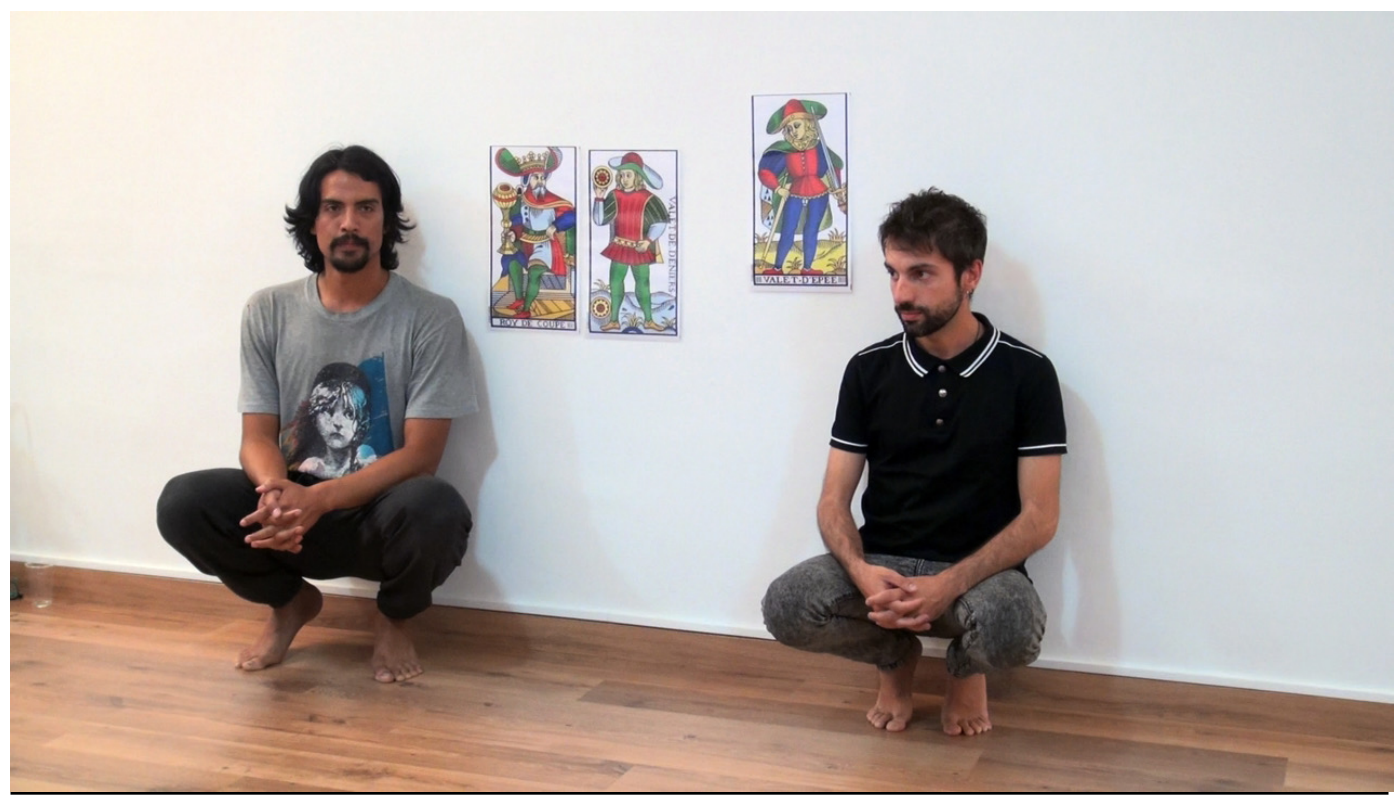

Figura 4. Constelación tarológica en Barcelona (octubre de 2018). Javi Moreno a la derecha.

\section{Conclusiones}

A partir de los resultados expuestos podemos concluir que siendo el Tarot de Marsella un juego de símbolos elaborado entre la Baja Edad Media y el Renacimiento, su iconografía tiene la suficiente permeabilidad para adaptarse a tiempos actuales y plantear identificaciones o transferencias pedagógicas entre la diversidad de personas que se acercan a él. Entre los 22 Arcanos Mayores y las 16 Figuras podemos encontrar personajes intergeneracionales, masculinos, femeninos, no binarios, polígamos, asexuales, religiosos o profanos. En tanto que imágenes sugestivas (casi de carácter onírico en ocasiones) permiten su uso sin necesidad de conocer sus significados. Se ha observado que facilitan sinergias y dinámicas de grupo a partir del azar o la selección de símbolos de acuerdo a gustos personales, cuestión que hace incluir variables nuevas e inesperadas en los posicionamientos de los estudiantes.

En ese sentido hemos observado que las constelaciones tarológicas se configuran como una herramienta pedagógica que potencia la asociación libre y el pensamiento creativo, detonando respuestas inesperadas, fuera de la zona de confort. Aplicado a la praxis artística observamos que puede ser aplicable en cualquier fase de un proyecto artístico y favorece su comprensión pedagógica. Como pre-producción, es decir, como una estrategia creativa que ayuda a pensar de manera encarnada sobre lo que deseamos producir. Como producción, planteándose la propia constelación como una obra performática en si misma, de carácter irrepetible. Y finalmente desde la post-producción, donde la experimentaciones e investigaciones previas derivan en eventos, piezas o espectáculos de mayor envergadura.

Dentro de la parte procedimental hemos contrastado a lo largo de los años que, aunque en grupos más experimentados se puede realizar de un modo más libre (dilatando el tiempo de 


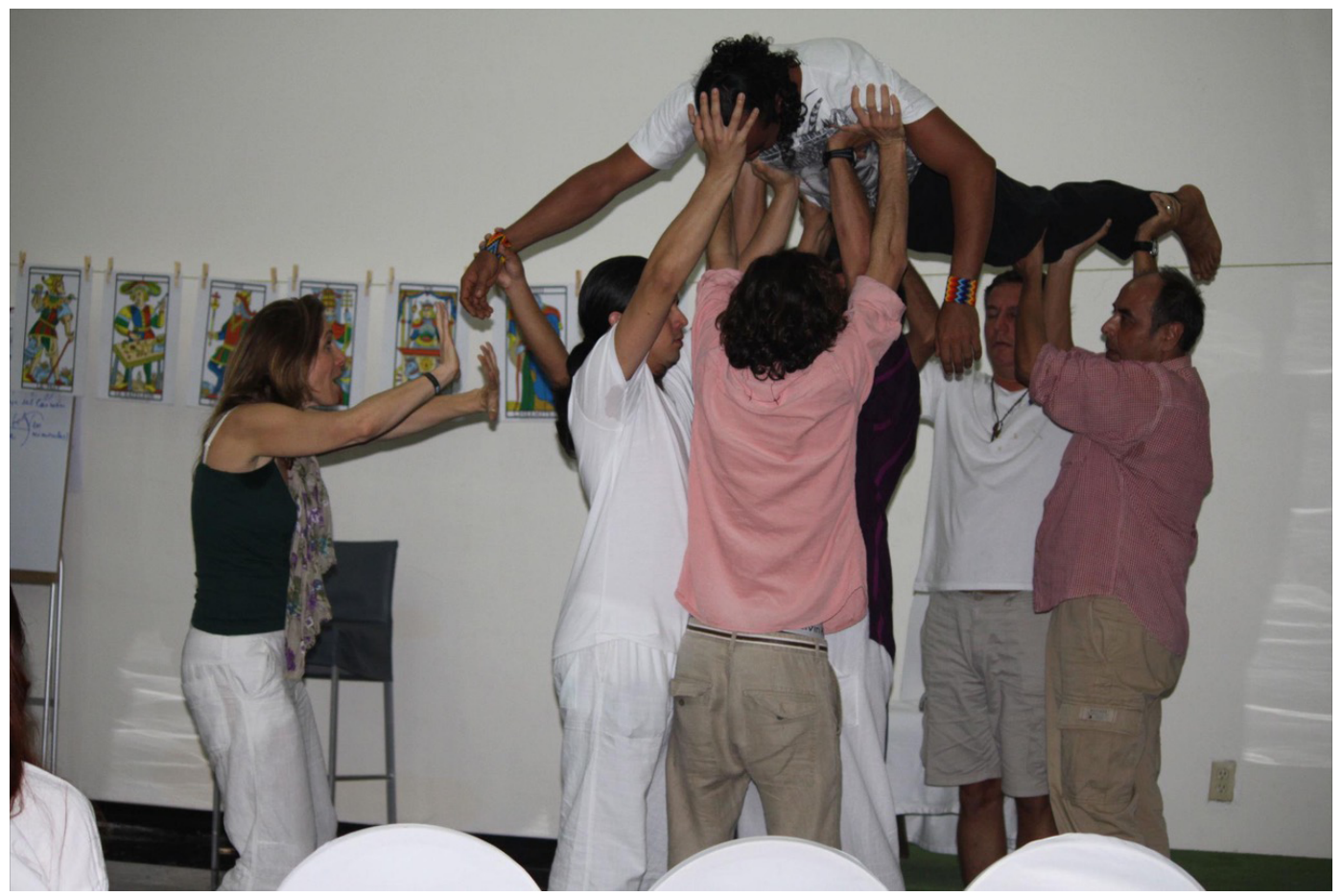

Figura 5. Grupo de hombres constelando en Cancún bajo la mediación de Marianne Costa.

la experiencia, por ejemplo), se recomienda que exista siempre una persona con experiencia que pueda medir el tiempo, inducir a estados de presencia corporal y mediar con los posibles bloqueos psíquico-físicos de las personas participantes. La causa principal es poder llegar a generar un conflicto o clímax (narrativo o no) que pueda resolverse finalmente. El proceso suele necesitar de una resolución. Hemos comprobado que el número mínimo idóneo suele ser de 8 personas, donde 5 practican la acción, 2 personas observan y 1 modera. Con 5 personas se consigue crear ya un espacio conflictivo entre personajes y un nudo argumental. Las dos visiones del público permiten averiguar que quien mira, también interpreta, y se tiene la valoración de las acciones consteladas desde como mínimo dos puntos de vista (más el de la persona moderadora). También observamos la importancia de incluir elementos y objetos versátiles para que el cuerpo entre en relación con un entorno mínimamente socializado (sillas, cañas, mesas, balones, etc.). Algo que proviene de noción lecoqiana del teatro del objeto y que ofrece una gran versatilidad de situaciones posibles.

En respuesta a los objetivos de la investigación y desde una encrucijada de saberes donde se ofrece legitimidad a los dos hemisferios cerebrales, las constelaciones tarológicas ayudan a la interpretación del Tarot de Marsella a devolverle una condición multidimensional, artística, encarnada y ceremonial. El espacio-tiempo creado tendrá siempre un matiz liminal y ritual, al igual que numerosas performances desarrolladas durante el siglo XX, donde la presencia de los performers y el público, y la sacralización de momento y del lugar, permiten darle forma a todo aquello interno, invisible y poco asible. Facilitan, en definitiva, una comunicación encarnada que trasciende la propia palabra y una expansión de los afectos en medio de una experiencia artística viva. 


\section{Referencias bibliográficas}

Costa, M. (2021). El Tarot paso a paso. Grijalbo

Costa, M., Jodorowsky, A. (2004). La vía del Tarot. Siruela

Costa, M., Jodorowsky, A. (2011). Metagenealogía. Siruela

Ferrer, E. (2007). Utopía y performance. Recogido en Performancelogía. http:// performancelogia.blogspot.com/2007/01/utopa-y-performance-esther-ferrer.html

Fischer-Lichte, E. (2016). Experiencia estética como experiencia umbral. En Revista de Teoría del Arte, 18, 79 - 100. https://revistateoriadelarte.uchile.cl/index.php/RTA/article/ view/39056/40705

Freud, S. (1912). Sobre la dinámica de la transferencia. Sigmund Freud. Tomo XII. Amorrortu

Gendlin, E. (2020). Focusing. Proceso y técnica del enfoque corporal. Mensajero

Irwin, R.L., Cosson, A. (2004). A/r/tography: Rendering self through arts-based living inquiry. Pacific Educational Press. Traducido por García, D. (trad.) (2013). La práctica de la a/r/tografía. En Revista Educación y Pedagogía, 25, 65-66. Universidad de Antioquía

Marteau, P. (1985). El Tarot de Marsella. Edaf

Panofsky, E. (2001). Estudios sobre iconología. Alianza editorial

Rufino, L. (2018). Pedagogias das encruzilhadas. En Revista Periferia, v. 10, n. 1, 71-88. Traducido en Diversa. http://www.diversidadreligiosa.com.ar/blog/exu-y-la-pedagogiade-las-encrucijadas/

Salvatierra Capdevilla, C. (2017). La Escuela Jacques Lecoq: una pedagogía para la creación dramática (Doctora). Universitat de Barcelona. 